\title{
Non-contact Measurement of Thickness Uniformity of Chemically Etched Si Membranes by Fiber-Optic Low-Coherence Interferometry
}

\author{
Zoran Djinovic ${ }^{1,3}$, Milos Tomic², Lazo Manojlovic ${ }^{3}$, \\ Zarko Lazic ${ }^{4}$ and Milce Smiljanic ${ }^{4}$ \\ ${ }^{1}$ Vienna University of Technology, ISAS, Floragasse 7, Vienna, \\ Institut bezbednosti, Kraljice Ane BB, Belgrade, \\ ${ }^{3}$ Integrated Microsystems Austria, Viktor Kaplan str. 2, Wr. Neustadt, \\ IInstitute of Microelectronics and Single Crystals, IHTM, Njegoseva 12, Belgrade, \\ 1,3 Austria \\ 2,4Serbia
}

\section{Introduction}

Micromachining of bulk $\mathrm{Si}$ is, nowadays, a matured technology in production of microelectromechanical (MEMS) devices such as freestanding mechanical structures like beams and membranes (Kovacs et al., 1998). There are two main techniques currently in use; wet and dry etching. The first one, particularly the anisotropic wet etching, is very often in standard production chain of piezoresistive pressure sensor (Sugiyama et al., 1983).

However, it is recognized very fast that etch uniformity across a wafer strongly depends on the crystal orientation of $\mathrm{Si}$ and type of etchant. This usually results with non-uniformity of the membrane thickness all around the Si wafer or within the membrane itself. (Dibi et al., 2000) report on the strong influence of the Si membrane flatness on the piezoresistive pressure sensor response. The main reason for the sensitivity loss of pressure sensor is the lack of parallelism of the two membrane sides. They found that flatness non-uniformity less than $1 \%$ on $30 \mu \mathrm{m}$ membrane causes electrical response loss of about $3 \%$. Also, they found that irregularity of the etched surface could be an important reason for the voltage offset of the final sensor. Because of that it is of paramount significance to know the final thickness of the membrane as well as the thickness uniformity across the wafer and membrane itself.

There is a list of papers (Bernstein et al., 1988; Tosaka et al., 1995; Mesheder \& Koetter, 1999) dealing with different measuring techniques. The most interesting are optical techniques being fast, nondestructive and offer in situ measurement of $\mathrm{Si}$ membrane thickness during the etching. (Bernstein et al., 1988) adopted a commercial reflectance spectrometer to measure Si membrane thickness. The main drawback was that the instrument could work well in the range of 0.1-5 $\mu \mathrm{m}$ only. (Tosaka et al., 1995) developed a method for in situ monitoring of the $\mathrm{Si}$ diaphragm thickness based on multiple-beam interference spectroscopy. Again, the main limitation of the method was the measuring range of 2-20 $\mu \mathrm{m}$ of the membrane thickness. Additionally, the light spot on the diaphragm was $200 \mu \mathrm{m}$ in

Source: Micro Electronic and Mechanical Systems, Book edited by: Kenichi Takahata,

ISBN 978-953-307-027-8, pp. 572, December 2009, INTECH, Croatia, downloaded from SCIYO.COM 
diameter that was the reason for the reduced space resolution. (Mesheder \& Koetter, 1999) proposed transmission spectroscopy technique for in situ measurement of membrane thickness based on fiber-optic bundle for illuminating of the target. The technique works well but only in the range of $10-500 \mu \mathrm{m}$ of thickness. The overall accuracy of the method is determined by the wafer homogeneity and accuracy of the initially measured wafer thickness.

In this paper we propose a contactless fiber-optic interferometric technique applicable for the fast and accurate measurement of the membrane thickness with accuracy of about $100 \mathrm{~nm}$. The method is based on low coherence interferometry, performed by "all-in-fiber" sensing configuration that is described in more details in (Djinovic et al. 2005; Tomic et al. 2002).

\section{Principle of operation}

Our sensing system is based on low-coherence interferometry performed in "all-in-fiber" Michelson interferometer shown in Fig. 1.

The core part of the sensing configuration is a fused $2 \times 2$ single mode $(9 / 125 \mu \mathrm{m})$ optical coupler. The input arms of the coupler are connected with a low-coherence light source (LCS) and photodetector (PD), an InGaAs photodiode. As a low-coherence light source (LCS) we used the a superluminescent diode, SUPERLUM SLD-56-M1, that emmits at 1300 $\mathrm{nm}$ with spectral width of about $40 \mathrm{~nm}$ at FWHM. The outlet arms are directed to the Si membrane (sensing arm) and to the mirror (reference arm).

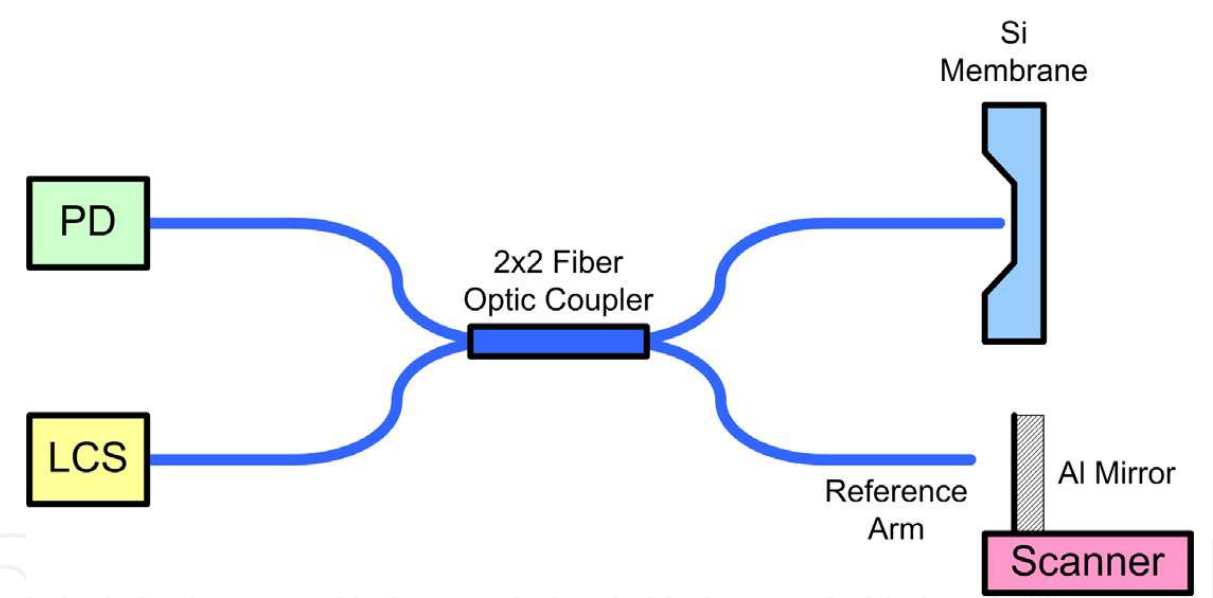

Fig. 1. Schematic presentation of "all-in-fiber" Michelson interferometer, LCS-white-light source, PD-photodiode

\subsection{Algorithm}

In Fig. 2 we depict a typical interferometric raw signal that we captured by photodiode. There are several characteristic low-coherence interferometric patterns that reflect the change of the transmitting media of low-coherence light. The four patterns, designed by 1,2 , 3 and 4 are important for the measurement.

The first pattern is the result of interference of the back reflected signal from the end of the sensing fiber and mirror in the reference arm. The second large pattern comes up due to interference between the light beams back-reflected from the front Si membrane surface and mirror in the reference arm. The third one is the result of interference of the back reflected 
light beam from the rear Si membrane surface. The fourth one comes due to the multiple reflections inside the membrane and it is not important for the further analyze.

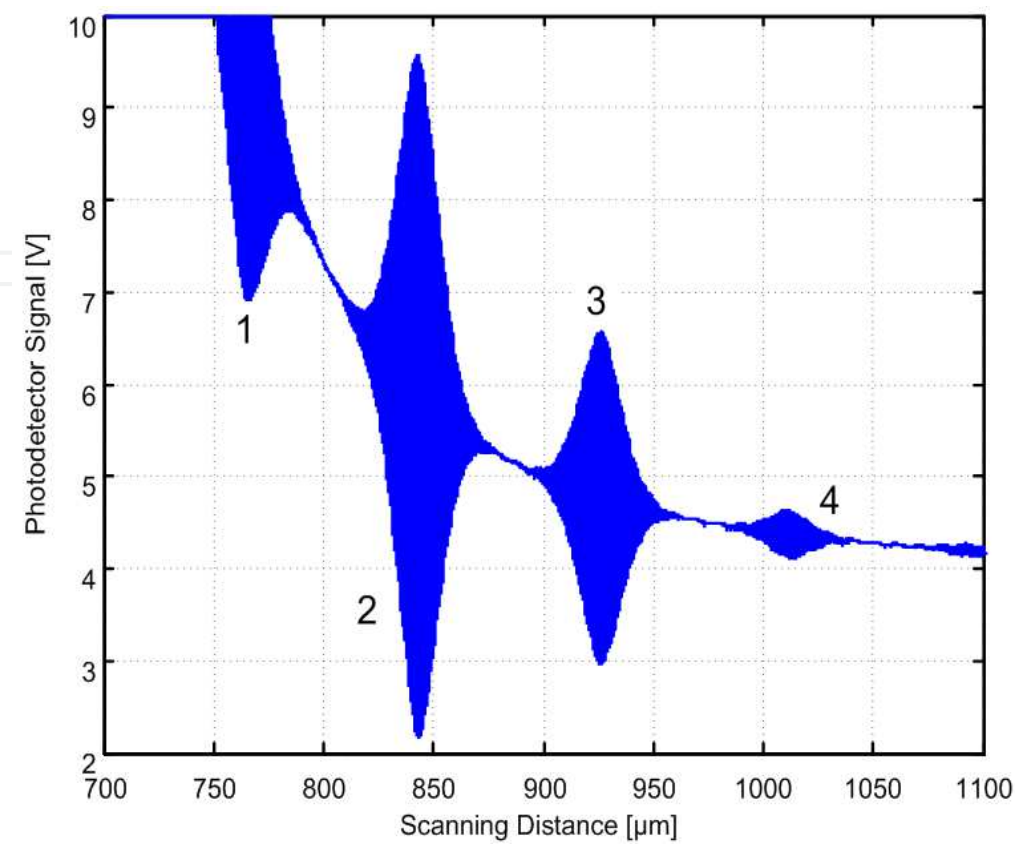

Fig. 2. Raw photodiode signal obtained by measurement of Si membrane thickness

From the raw signal it is difficult to extract the optical path difference between the interferograms. For that reason we need to make the basic signal processing consisted of high-pass filtering and envelope detection. In Fig. 3a is given the diagram of filtered signal without DC component together with the detected envelope in Fig. 3b. In this diagram is presented a part of the processed signal around the second interferometric pattern.

Based on the fitting of the detected envelope with the Gaussian curve it is possible to obtain the position of the zero optical path length difference. In Fig. 4a is given the detected envelope together with the fitted sum of the Gaussian functions (Fig. 4b). In Fig. 4b is presented part of the processed signal around the second interferometric pattern.

\section{Experiment}

Fig. 5 shows a close look to the sensing fiber directed against the etched side of the 3 inch $\{100\} \mathrm{Si}$ wafer in $\mathrm{KOH}$ solution according to the sensing configuration depicted in Fig. 1. We measured the thickness of the flat membranes and membranes with central boss. The last one is schematically presented in Fig. 6 . The overall dimensions are $2 \times 2 \mathrm{~mm} 2$.

We measured the membrane thickness and uniformity by scanning of one single membrane in $\mathrm{x}-\mathrm{y}$ direction, subjecting several membranes in central part of the wafer and several membranes all around the periphery of the wafer.

\section{Results and discussion}

We calculated the optical path that light beam has passed through the membrane by determining of the distance difference between the central position of the second and third interferometric pattern. According to the algorithm we determined the central position of the interferometric patterns of interest by fitting of Gaussian functions. We determined this 


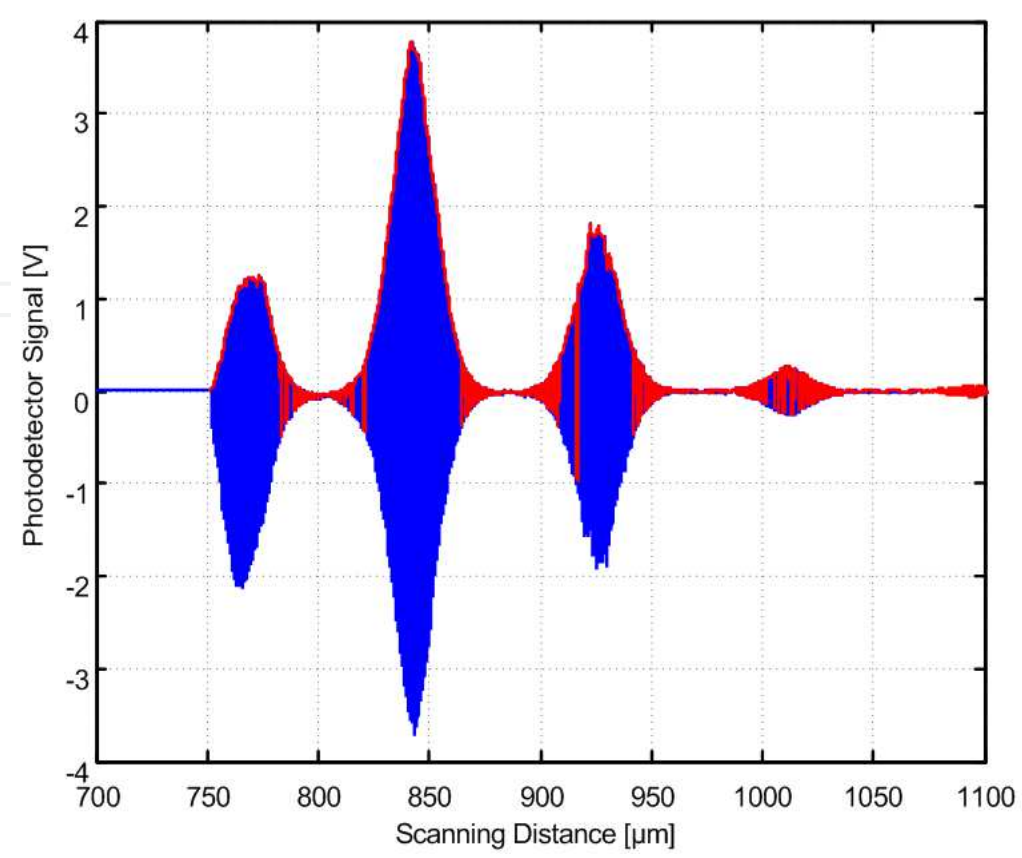

a)

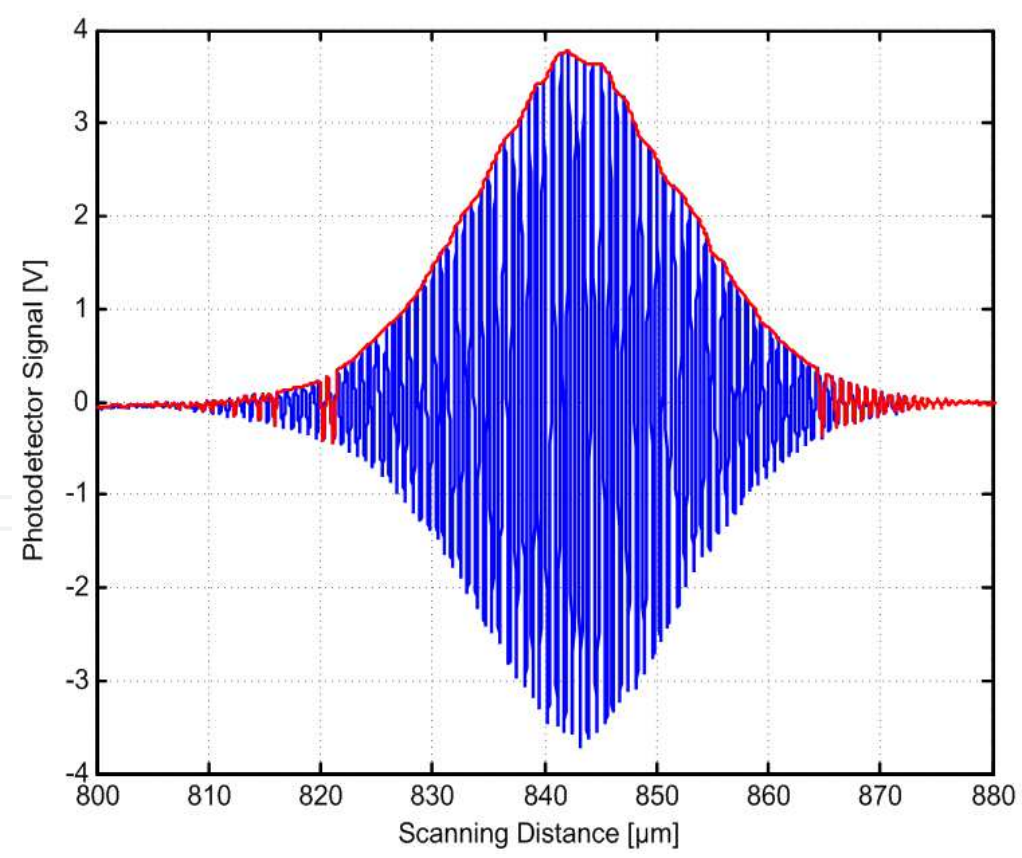

b)

Fig. 3. Filtered signal (a) and detected envelope (b). In the (b) diagram is presented part of the processed signal around the second interferometric pattern 


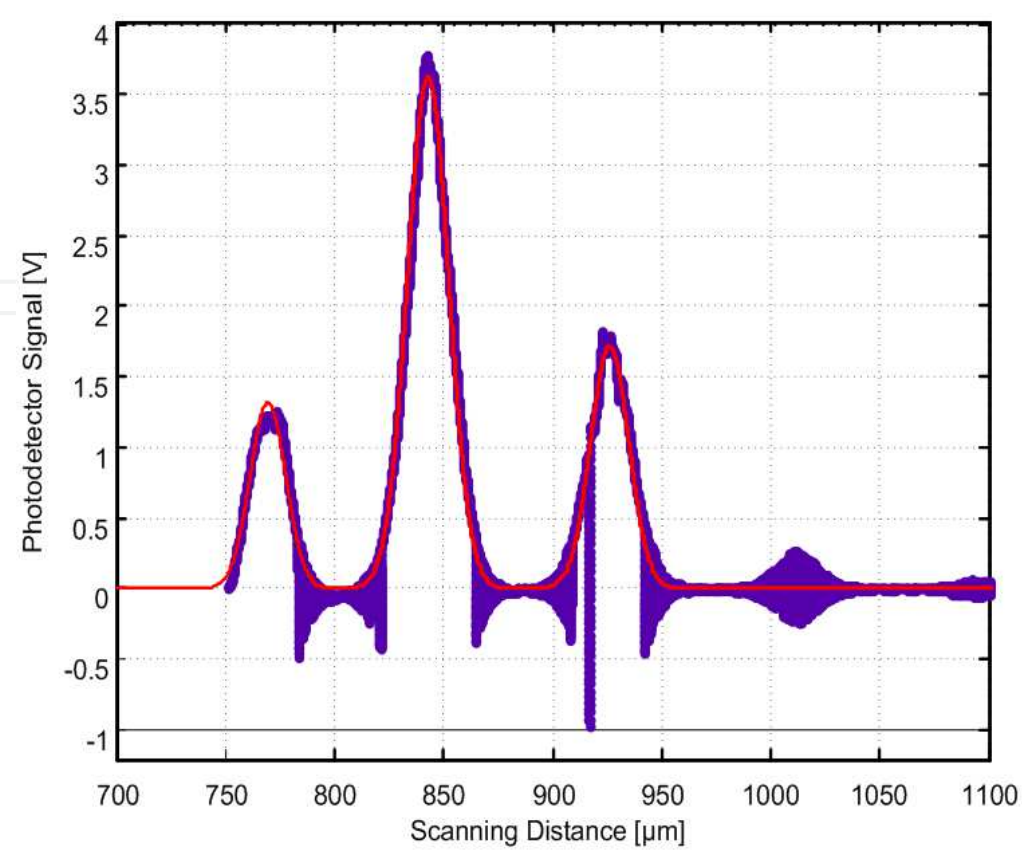

a)

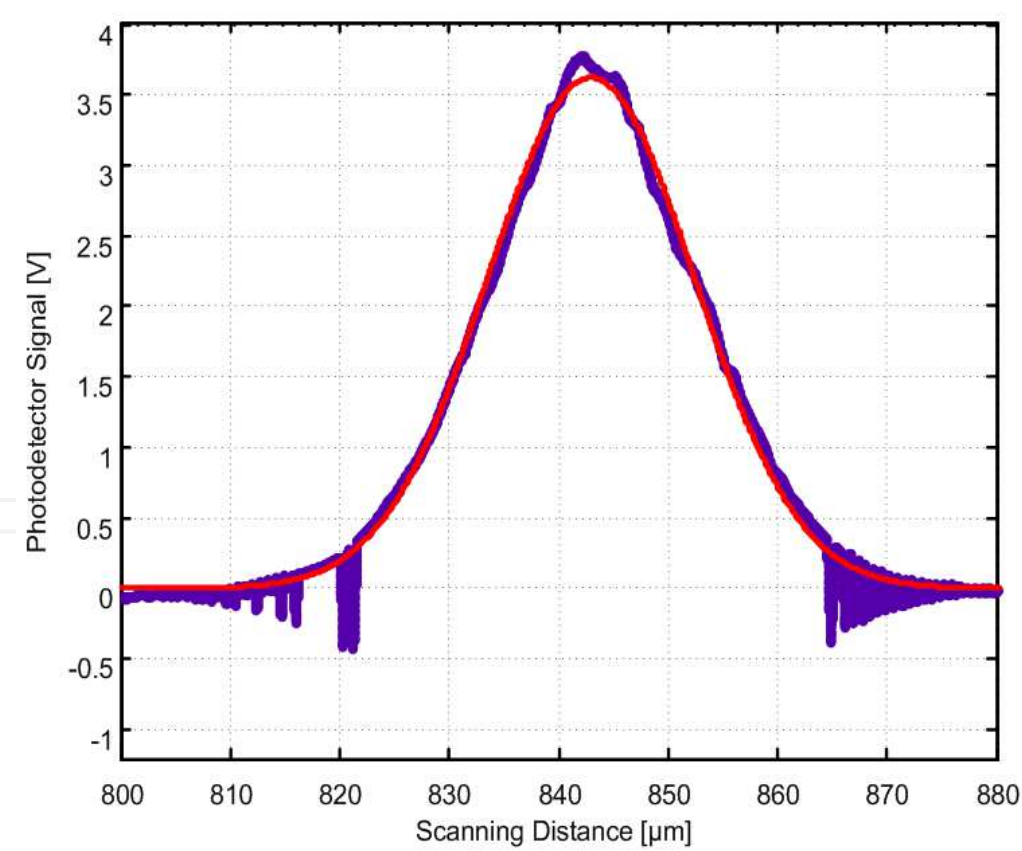

b)

Fig. 4. Detected envelopes (a) and fitted sum of the Gaussian functions (b). In the (b) diagram is presented part of the processed signal around the second interferometric pattern 


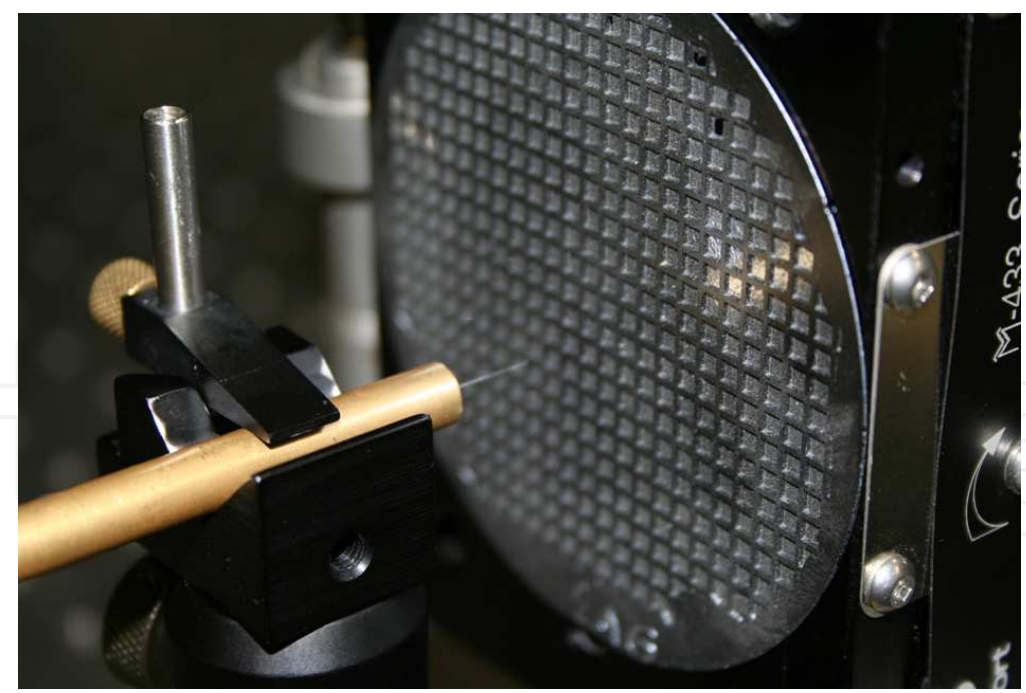

Fig. 5. Close look to the sensing fiber and 3 inch $\{100\} S i$ wafer with chemically etched membranes

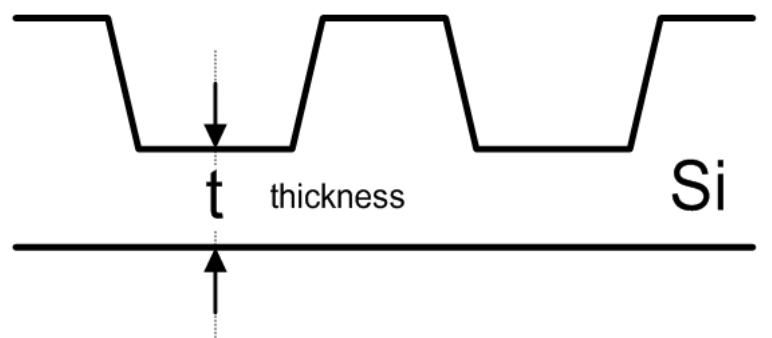

Fig. 6. Cross-section of one silicon membrane with central boss. $t$ is the membrane thickness

position with accuracy of about $100 \mathrm{~nm}$. The value of the difference between the central peaks is an optical thickness, $t_{\mathrm{opt}}$ of the membrane. Using the simple relation $\left(t_{\mathrm{opt}}=t_{\text {phys }} n\right)$ between the optical path and refraction index, $n$ of $\mathrm{Si}\left(n=3.5085 @ 1300 \mathrm{~nm}, 23^{\circ} \mathrm{C}\right)$ we calculated the physical thickness, $t_{\text {phys }}$ of the membrane.

Fig. 7 presents the results of calculation of physical thicknesses within the one subjected $\mathrm{Si}$ membrane with central boss along the $300 \mu \mathrm{m}$ long line in peripheral zones of the membrane (left, right, up and down part of the membrane). Measuring points have been obtained by probing after every $50 \mu \mathrm{m}$. We obtained the average thickness of the membrane of $27.3 \mu \mathrm{m}$ with uniformity in the range of $\pm 0.4 \mu \mathrm{m}$. We also measured the roughness uniformity along all four peripheral zones of the $\mathrm{Si}$ wafer. We obtained average roughness of $\pm 1.7 \mu \mathrm{m}$.

We also performed measurement of the membrane thickness of four membranes around the central one. In this measurement we obtained the average thickness of five central membranes of $27.8 \mu \mathrm{m}$ and uniformity of about $\pm 0.7 \mu \mathrm{m}$. To obtain the overall thickness and uniformity of the membranes at periphery of the wafer we measured the thickness of four membranes at the edges of the wafer. In this case we obtained average thickness of $25.6 \mu \mathrm{m}$ and uniformity of about $\pm 1.7 \mu \mathrm{m}$.

Using the same setup we measured the thickness and roughness of the membrane around the outer rim in the near proximity to the edge. Measuring points have been obtained by probing after every $10 \mu \mathrm{m}$ in the range of $50 \mu \mathrm{m}$. The results are given in Fig. 8. The average thickness is $23.9 \mu \mathrm{m}$ and the uniformity of $\pm 0.11 \mu \mathrm{m}$. The roughness of the surface is $\pm 0.23 \mu \mathrm{m}$. 

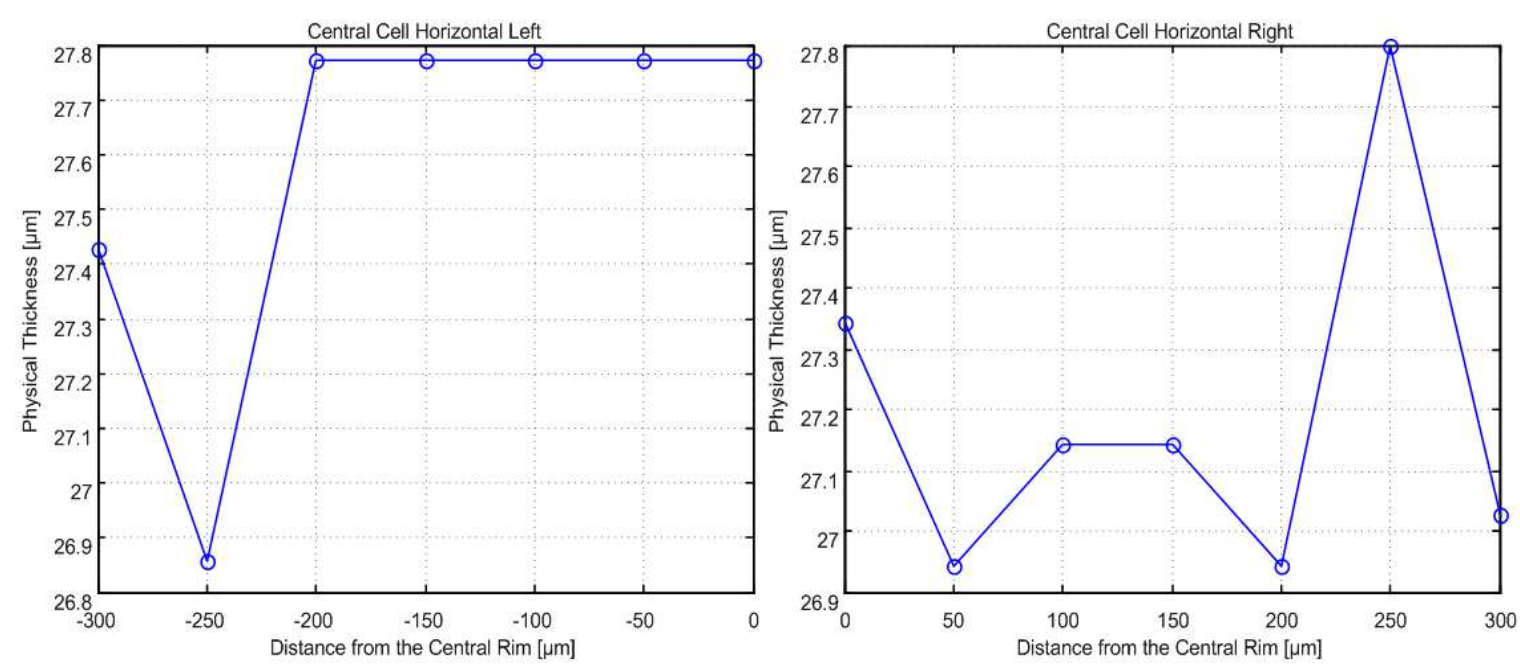

(a)
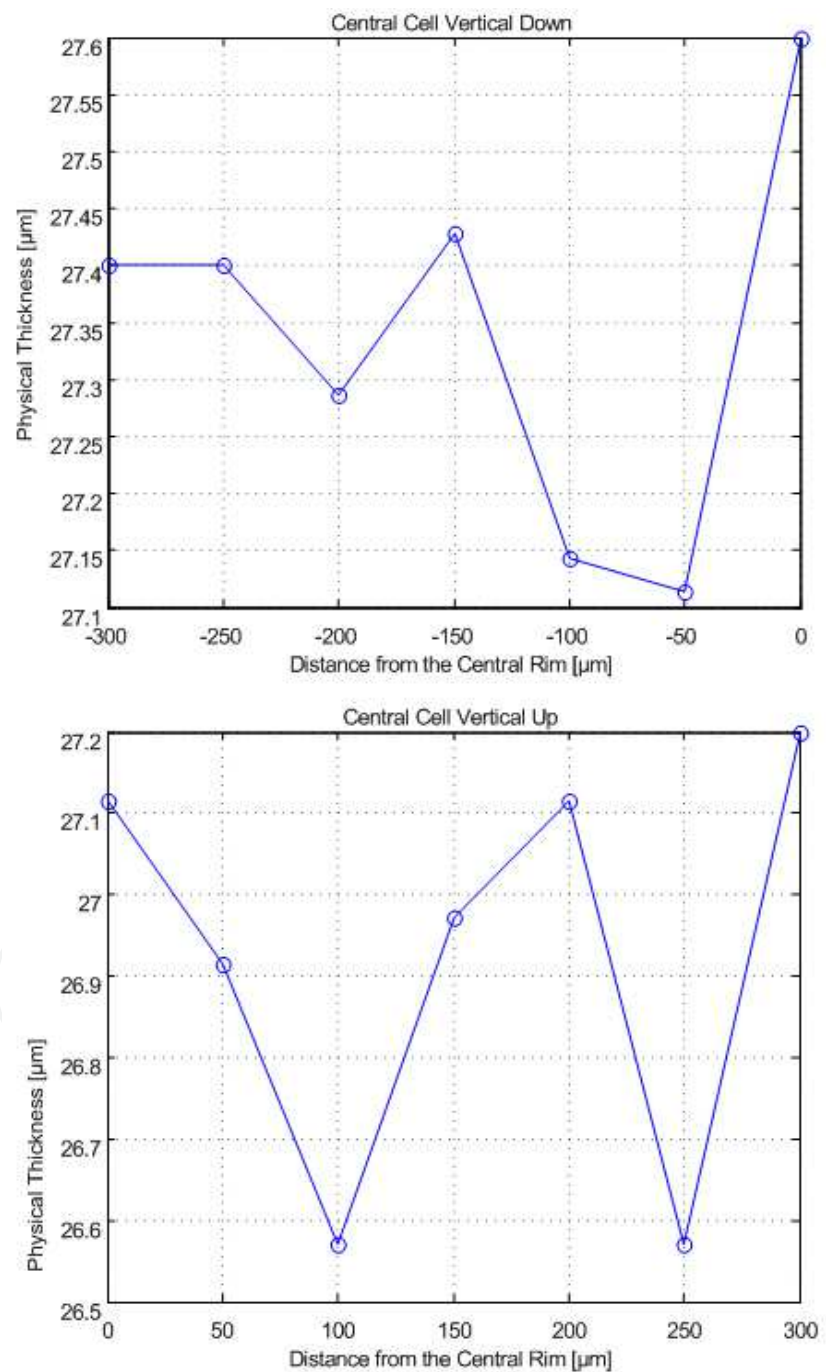

(b)

Fig. 7. Thicknesses within the one subjected Si membrane with central boss along the $300 \mu \mathrm{m}$ long line in peripheral zones of the membrane (a) left and right; (b) up and down part of the membrane 


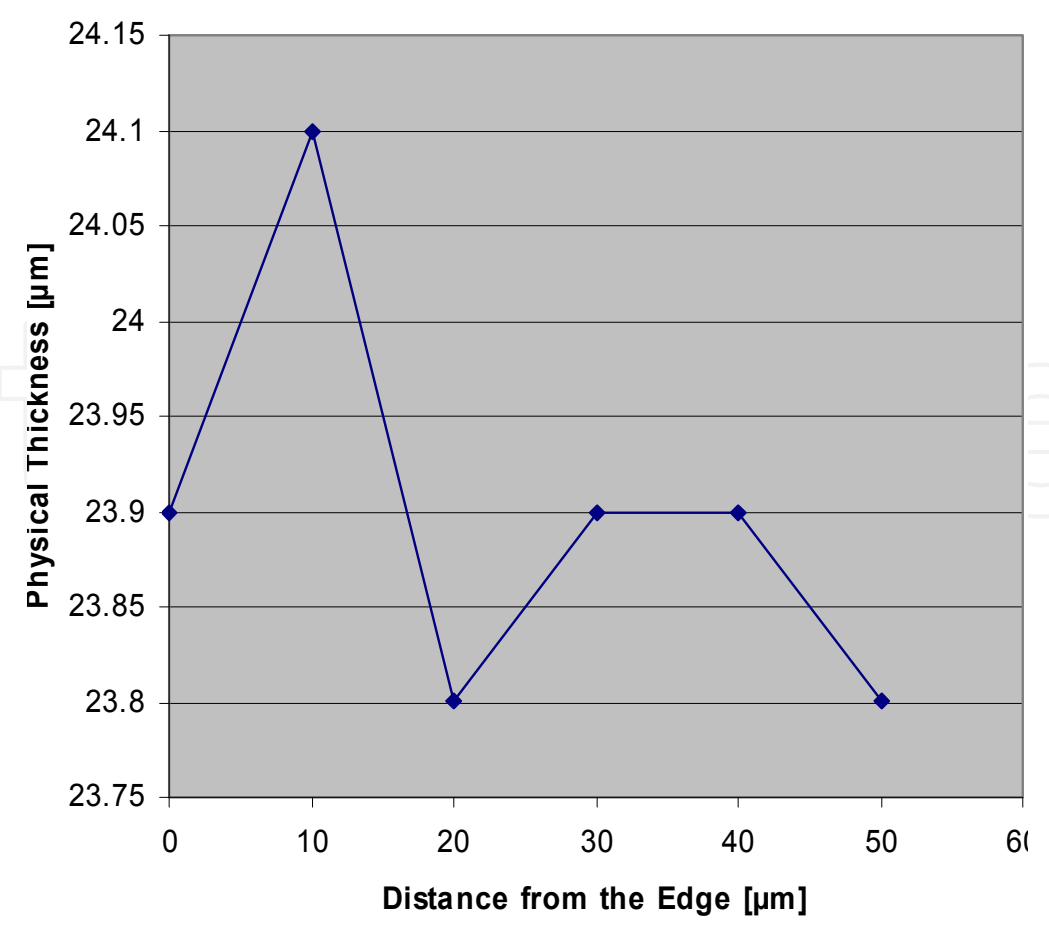

(a)

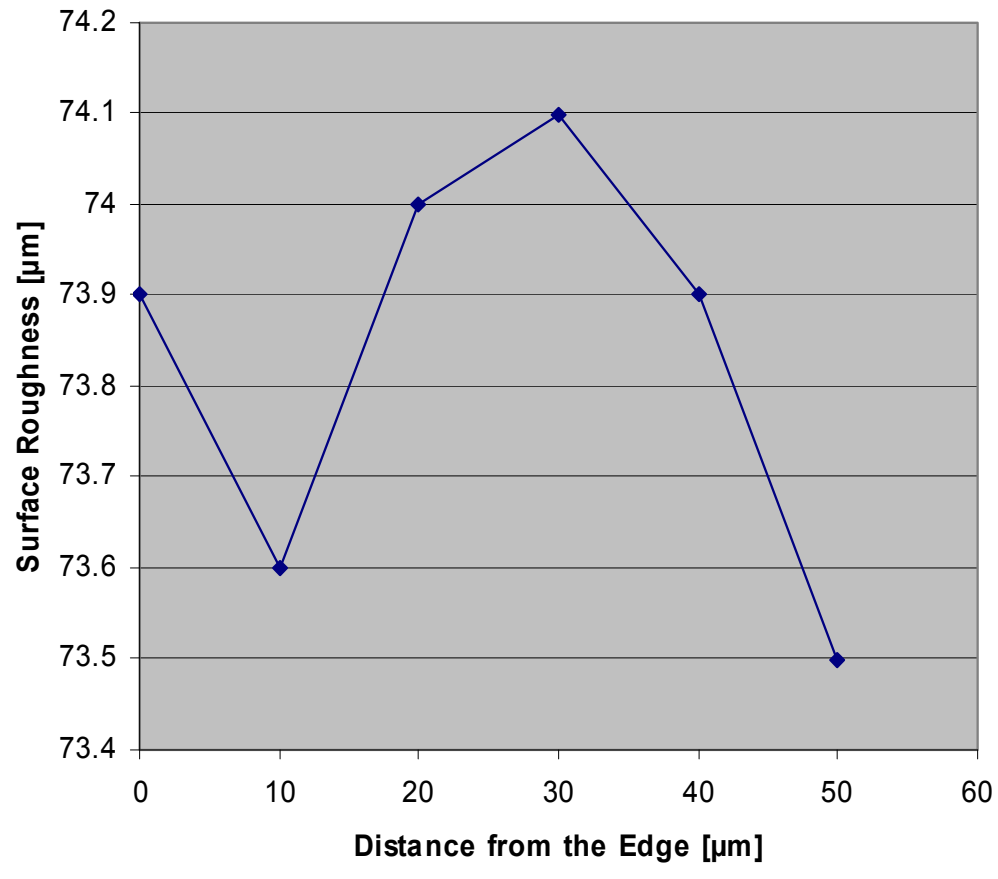

(b)

Fig. 8. Thickness (a) and roughness (b) of the membrane in the close proximity to the rim and edge

Fig. 9 presents the results of calculation of physical thicknesses within the one subjected flat Si membrane along the $200 \mu \mathrm{m}$ long line in central zone of the membrane. Measuring points have been obtained by probing after every $10 \mu \mathrm{m}$. We obtained the average thickness of the membrane of $30 \mu \mathrm{m}$ with uniformity in the range of $\pm 0.5 \mu \mathrm{m}$. We also measured the thickness 
uniformity along the central zone of the Si wafer, testing central part of 20 membranes. We obtained average thickness of $28,6 \mu \mathrm{m}$ with scattering of $\pm 1.6 \mu \mathrm{m}$.

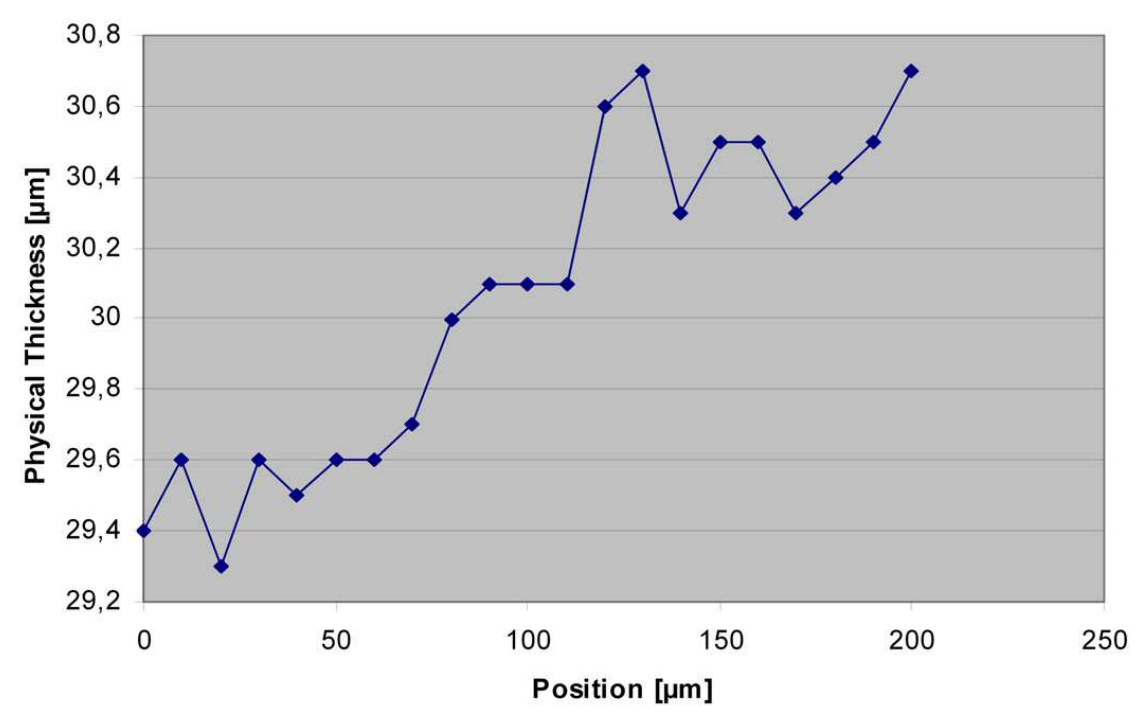

Fig. 9. Thickness uniformity within the one Si membrane of $2 \times 2 \mathrm{~mm}$ in overall dimensions

The above results (Fig. 7 and 8 ) show that anisotropic chemical etching of the central Si membrane generates relatively rough surface of $\pm 1.7 \mu \mathrm{m}$ while the thickness uniformity is much better of $\pm 0.4 \mu \mathrm{m}$. The first several neighbours have average membrane uniformity of $\pm 0.7 \mu \mathrm{m}$. However, the average membrane uniformity of peripheral membranes at the same wafer of $\pm 1.7 \mu \mathrm{m}$ shows that chemical etching along the circumference of the wafer is affected by concentration variation of $\mathrm{KOH}$ solution. Similar results are obtained by flat membranes presented in Fig. 9. Such results are in accordance with findings given in (Dibi et al. 2000).

\section{Conclusion}

We presented here one contact-less optical technique based on low-coherence interferometry for measurement of thickness and uniformity of $\mathrm{Si}$ membranes. We performed a single-mode fiber-optic sensing configuration that is also applicable for the in situ measurement of membrane thickness. Space resolution was defined by diameter of spot of the impinging light of about $20 \mu \mathrm{m}$. The accuracy of the technique is about $100 \mathrm{~nm}$.

\section{Acknowledgement}

The authors would like to thank the Austrian Science Fund (FWF) for funding this research under the Project L139-N02 "Nanoscale measurement of physical parameters" and the Integrated Microsystems Austria, IMA GmbH that partially supported the research activities in this paper.

\section{References}

Kovacs, G.T.A.; Maluf, N.T. \& Petersen, K.E. (1998). Bulk micromachining of silicon, Proceeding of the IEEE, Vol. 86, pp.1536-1551 
Sugiyama, S.; Takigawa, M. \& Igarski, I. (1983). Integrated piezoresistive pressure sensor with both voltage and frequency output, Sensor and Actuators A, 4 (1983) 113-120

Dibi, Z.; Boukabache, A. \& Pons, P. (2000). Effect of the silicon membrane flatness defect on the piezoresistive pressure sensor response, Proceedings of the 7th IEEE International Conference on Electronics, Circuits and Systems, ICECS 2000, Vol. 2, pp. 853- 856

Bernstein, J.; Denison, M. \& Greiff, P. (1988). Optical measurement of silicone membrane and beam thickness using a reflectance spectrometer, IEEE Transactions on Electronic Devices, 35 (1988) 801-803

Tosaka, H. ; Minami, K. \& Esashi, M. (1995). Optical in situ monitoring of silicon diaphragm thickness during wet etching, J. Micromech. Microeng. , 5 (1995) 41-46

Mescheder, U. M. \& Ch. Koetter, Ch. (1999). Optical monitoring and control of Si wet etching", Sensors and Actuators, 76 (1999) 425-430

Djinovic, Z.; M. Tomic, M. \& Vujanic, A. (2005). Nanometer scale measurement of wear rate and vibrations by fiber-optic white light interferometry, Sensors and Actuators, A123-124 (2005) 92-98

Tomić, M; J. Elazar, J. \& Djinović, Z. (2002). Low-coherence interferometric method for measurement of displacement based on a $3 \times 3$ fibre-optic directional coupler, J. Opt. A: Pure Appl. Opt. 4, (2002) 381-386 


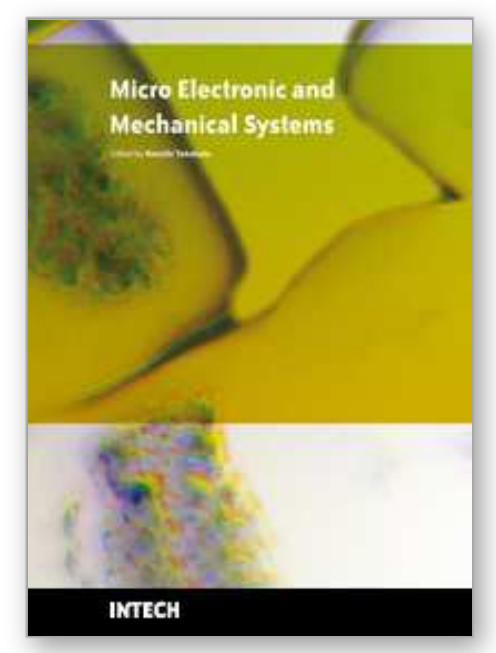

\section{Micro Electronic and Mechanical Systems}

Edited by Kenichi Takahata

ISBN 978-953-307-027-8

Hard cover, 386 pages

Publisher InTech

Published online 01, December, 2009

Published in print edition December, 2009

This book discusses key aspects of MEMS technology areas, organized in twenty-seven chapters that present the latest research developments in micro electronic and mechanical systems. The book addresses a wide range of fundamental and practical issues related to MEMS, advanced metal-oxide-semiconductor (MOS) and complementary MOS (CMOS) devices, SoC technology, integrated circuit testing and verification, and other important topics in the field. Several chapters cover state-of-the-art microfabrication techniques and materials as enabling technologies for the microsystems. Reliability issues concerning both electronic and mechanical aspects of these devices and systems are also addressed in various chapters.

\section{How to reference}

In order to correctly reference this scholarly work, feel free to copy and paste the following:

Zoran Djinovic, Milos Tomic, Lazo Manojlovic, Zarko Lazic and Milce Smiljanic (2009). Non-Contact Measurement of Thickness Uniformity of Chemically Etched Si Membranes by Fiber-Optic Low-Coherence Interferometry, Micro Electronic and Mechanical Systems, Kenichi Takahata (Ed.), ISBN: 978-953-307-027-8, InTech, Available from: http://www.intechopen.com/books/micro-electronic-and-mechanical-systems/noncontact-measurement-of-thickness-uniformity-of-chemically-etched-si-membranes-by-fiber-optic-low

\section{INTECH}

open science | open minds

\section{InTech Europe}

University Campus STeP Ri Slavka Krautzeka 83/A 51000 Rijeka, Croatia Phone: +385 (51) 770447 Fax: +385 (51) 686166 www.intechopen.com

\author{
InTech China \\ Unit 405, Office Block, Hotel Equatorial Shanghai \\ No.65, Yan An Road (West), Shanghai, 200040, China \\ 中国上海市延安西路65号上海国际贵都大饭店办公楼 405 单元 \\ Phone: +86-21-62489820 \\ Fax: +86-21-62489821
}


(C) 2009 The Author(s). Licensee IntechOpen. This chapter is distributed under the terms of the Creative Commons Attribution-NonCommercialShareAlike-3.0 License, which permits use, distribution and reproduction for non-commercial purposes, provided the original is properly cited and derivative works building on this content are distributed under the same license. 